\title{
TEM Investigation on Ceramic Strengthening NiAl-Based Composite Prepared by Thermal Explosion and Hot Extrusion
}

\author{
L.Y. Sheng, C. Lai, T.F. Xi \\ Shenzhen Key Laboratory of Human Tissue Regeneration and Repair Shenzhen Institute \\ Peking University \\ Shenzhen, China
}

\begin{abstract}
The NiAl-based composite strengthened by $\mathrm{TiC}$ and Al2O3 was synthesized by thermal explosion and hot extrusion. Its microstructure and mechanical properties were investigated by XRD, OM, TEM and HRTEM. The results reveal that the NiAl-TiC- Al2O3 composite can be densified with less porosity. The NiAl grain of the composite matrix has been well refined by the $\mathrm{TiC}$ and $\mathrm{Al} 2 \mathrm{O} 3$ particles. In addition, stacking fault and microtwins formed in some $\mathrm{TiC}$ particles and thin amorphous layer also observed along $\mathrm{NiAl} / \mathrm{TiC}$ interface. Moreover Ti2AIC particle with intergrowth $\mathrm{TiC}$ plate inside is formed along the NiAl grain boundary.
\end{abstract}

Keywords-NiAl-based composite; TEM; ceramic particle; microstructure

\section{INTRODUCTION}

$\mathrm{NiAl}$ and its alloys have been studied widely and thought as one of most promising candidates to substitute the superalloy used in aeroengine, because of the good physical properties and excellent high temperature corrosion resistance of $\mathrm{NiAl}$ [1-4]. However, the room temperature (RT) brittleness, low room temperature fracture toughness and relative poor high temperature strength have restricted its applications [5-7]. Therefore, to overcome the shortcomings of the $\mathrm{NiAl}$, many techniques[8-11] have been adopted, among which fabricating $\mathrm{NiAl}$ based composites by adding stiffness particles is a convenient way to obtain improvement in high temperature properties. For example, boride strengthening NiAl based composite, oxide strengthening $\mathrm{NiAl}$ based composite and nitride strengthening $\mathrm{NiAl}$ based composite have been investigated extensively to incorporate the ceramics particles into the NiAl matrix [12,13]. Generally, NiAl based composite strengthened by ceramic particles can be obtained by reaction synthesis, which is an easy, quick and economic method [14-16]. However the porosity generated during the reaction synthesis is a big problem [17-19]. The recent study reveals that the thermal explosion and hot extrusion could fabricate composite with fine microstructure and less porosity [16]. Nevertheless, the poor RT ductility of the NiAl based composite still handicap its application as high temperature structure material. Fortunately, the excellent oxidation and wear resistance of $\mathrm{NiAl}$ make the $\mathrm{NiAl}$ based composite still has widely application prospect in environmental resistant fields [19]. Therefore, in the present paper the ceramic particles strengthening NiAl-based composite is fabricated thermal explosion and hot extrusion and its microstructure characteristics are studied as well.

\section{EXPERIMENTAL PROCEDURE}

Elemental powder mixtures including $\mathrm{Ni}(98 \%,<1 \mu \mathrm{m})$, $\mathrm{Al}(98 \%,<13 \mu \mathrm{m}), \mathrm{Ti}(99 \%,<75 \mu \mathrm{m}), \mathrm{TiO}_{2}(98 \%,<10 \mu \mathrm{m})$ and $\mathrm{C}(99.9 \%,<1 \mu \mathrm{m})$ for composites of NiAl-15vol TiC+2vol $\mathrm{Al}_{2} \mathrm{O}_{3}$ were dry mixed in a ball milling for $15 \mathrm{~h}$. The mixed powders were put into the thermal explosion and hot extrusion system [16]. Firstly, the mixed powders were pressed into compact and degassed; then the inductor heat reaction puncheon to $800 \mathrm{~K}$ to start the reaction synthesis. The temperature of the compact was detected by a thermal pair in the thermal explosion and hot extrusion synthesis system. When the reaction synthesis began, the temperature of the powder would increases dramatically. Then two second later, a force of $500 \mathrm{MPa}$ was imposed on the reaction puncheon in order to densify the synthesized composite.

The samples for microstructure observation and compression test were cut from the thermal explosion and hot extrusion synthesized $\mathrm{NiAl}-\mathrm{TiC}-\mathrm{Al}_{2} \mathrm{O}_{3}$ composite by electro-discharge machining (EDM). The resultant phases in the composite were characterized by X-ray diffraction (XRD) with a $\mathrm{Cu}$ radiation at $40 \mathrm{kV}$ and $40 \mathrm{~mA}$. Microstructural characterization of sample was carried out on an OLYMPUS GX41 Optical microscope (OM). Samples for OM observations were prepared by conventional methods of mechanical polishing and chemical etching with an acidic mixture $\left(\mathrm{CH}_{3} \mathrm{COOH} / \mathrm{HNO}_{3} / \mathrm{HCl}=8: 4: 1\right)$. The samples for transmission electron microscope (TEM) observation were cut by EDM. The slices were mechanically ground from both sides to $30 \mu \mathrm{m}$ and then thinned by ion milling. The thin foils were examined on a JEOL-2010 high-resolution transmission electron microscope with a point resolution of $0.19 \mathrm{~nm}$ and operated at $200 \mathrm{kV}$.

\section{RESULT AND DISCUSSION}

The NiAl-TiC composite with dispersed $\mathrm{Al}_{2} \mathrm{O}_{3}$ oxides were successfully fabricated by thermal explosion and hot extrusion. The $\mathrm{x}$-ray diffraction analysis proves that the elemental 
powders have been transformed to the NiAl phase after thermal explosion and hot extrusion processing, as shown in Figure. 1(a). The peaks of NiAl matrix and $\mathrm{TiC}$ phase are obvious, but the peak of $\mathrm{Al}_{2} \mathrm{O}_{3}$ is so weak that it can not be found in the XRD pattern. The typical microstructure of NiAl-TiC- $\mathrm{Al}_{2} \mathrm{O}_{3}$ composite is shown in Figure.1 (b). From the OM micrograph, it can be seen that the composite is mainly composed of NiAl Matrix and white TiC. In addition, there is still some porosity inside. The average grain size of the $\mathrm{NiAl}$ matrix is about ten microns. Additionally, the NiAl phase is elongated along the extrusion direction, which indicates that the composite experiences deformation during hot extrusion. The $\mathrm{TiC}$ particles with several microns mainly distributed along the $\mathrm{NiAl}$ grain boundaries, which can contribute to the grain refinement.
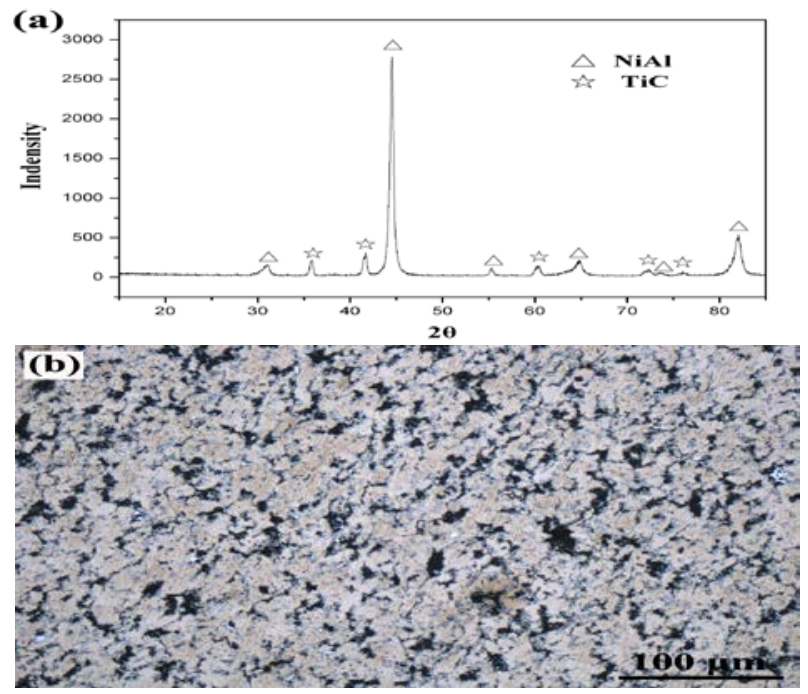

FIGURE I. (A) XRD PATTERN OF THE NIAL-TIC-AL2O3 COMPOSITE, (B) OPTICAL MICROGRAPH OF THE NIAL-TIC-AL2O3 COMPOSITE.

The TEM observation on the NiAl-TiC- $\mathrm{Al}_{2} \mathrm{O}_{3}$ composite is shown in Figure.2. The NiAl matrix has dual-grain structure, as shown in the Figure.2 (a). Except the large NiAl grain shown in Figure. 1(b), there are much fine grains with hundreds of nanometers. The TiC particles exhibit two kinds of morphologies. The TiC particles along the NiAl grain boundary agglomerate into big ones, as shown in Figure. 1(b). The TiC particle in NiAl grain exhibits polyhedron characteristics, as shown in Figure. 2(b). The inset selected area electron diffraction (SAED) pattern gives that $\mathrm{TiC}$ particle has an orientation relationship with NiAl matrix of $[100]_{\mathrm{TiC}} / /[100]_{\mathrm{NiAl}}$ and $(020)_{\mathrm{TiC}} / /(0-11)_{\mathrm{NiAl}}$, which was reported in the former research [12]. However, further observation on $\mathrm{NiAl}$ and $\mathrm{TiC}$ interface finds that an amorphous transition layer with several nanometers exists between $\mathrm{NiAl}$ and $\mathrm{TiC}$, as shown in Figure. 2(c). According to the recent research [19], the amorphous structure contains high energy and so unstable, especially to the amorphous obtained by mechanical alloying. The heat treatment will lead to the amorphous crystallization. In the present paper, the relative ball milling and rapid cooling during synthesis process may contribute much to the formation of amorphous. In addition, the crystal parameters of $\mathrm{NiAl}$ and $\mathrm{TiC}$ are $0.356 \mathrm{~nm}$ and $0.435 \mathrm{~nm}$, respectively. The big difference between them will lead to great interface stress. Based on the recent research [20], the high interface stress can result in the formation of amorphous film. Therefore it can be concluded that the formation of the amorphous layer should be attributed to the synthesis procedure and crystal difference. In addition, along the $\mathrm{NiAl}$ grain boundary, the $\mathrm{Al}_{2} \mathrm{O}_{3}$ particles with irregular shape were found, as shown in Figure.2 (d). By the SAED pattern, it can be confirmed that most of particles are $\alpha-\mathrm{Al}_{2} \mathrm{O}_{3}$.

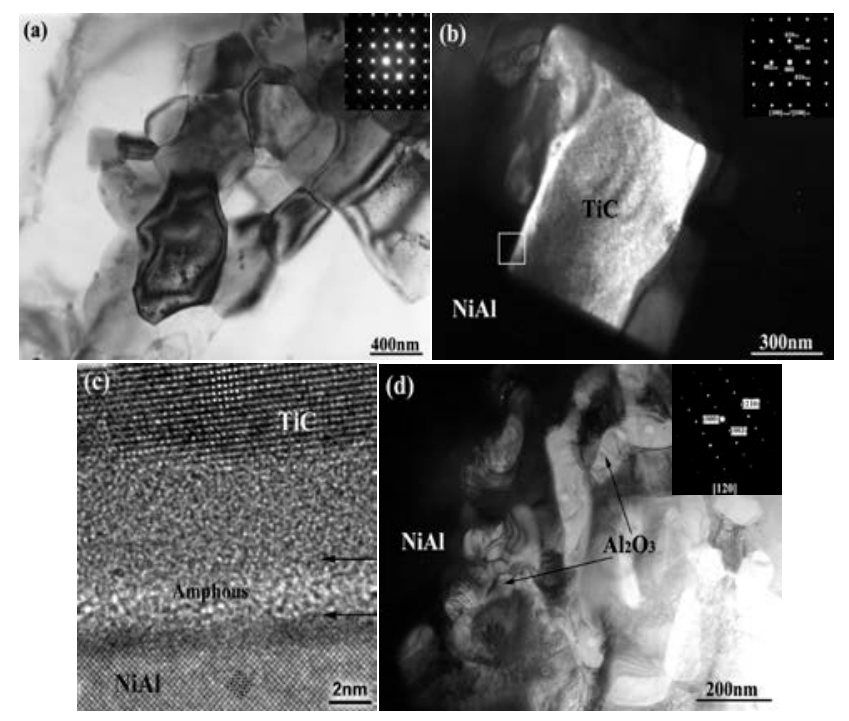

FIGURE II. (A) BRIGHT FILED TEM MICROGRAPH OF FINE NIAL MATRIX, (B) MORPHOLOGY OF TIC PARTICLE IN NIAL GRAIN, (C) HRTEM OF THE THIN AMORPHOUS LAYER ALONG NIAL/TIC PHASE INTERFACE, (D) MORPHOLOGY OF A-AL2O3 PARTICLES ALONG NIAL BOUNDARY (INSET PICTURES SHOWING THE CORRESPONDING SAED PATTERNS).

Further observations on the $\mathrm{TiC}$ particles find that some TiC particles have the laminate characteristic, as shown in Figure.3 (a). The inset SAED pattern confirms that stacking faults and microtwins exist inside. The corresponding HRTEM image is shown in Figure.3 (b), which reveals that the atoms on the twin boundary are different from the one in the twin crystal. The EDS test also shows that there are more $\mathrm{Al}$ and Ti elements in the TiC particle that contains microtwins and stacking faults defects. According to Yu's study [21], the segregation of $\mathrm{Al}$ and $\mathrm{Si}$ in $\mathrm{TiC}$ can obviously increase the formation chance of microtwins and stacking faults, so it may be drawn that the $\mathrm{Al}$ segregation leads to the formation of such defects. Moreover, some $\mathrm{Ti}_{2} \mathrm{AlC}$ ceramic particles are observed, which has hexagonal crystal with lattice parameters of $a=0.34 \mathrm{~nm}, \mathrm{c}=1.36$ $\mathrm{nm}$, as shown in Figure.3 (c). Inset SAED pattern reveals that there are stacking fault inside. The corresponding HRTEM image shows that except the stacking fault and microtwins inside there are some special intergrowth plates, as shown in Figure.3 (d). According to the recent study [22,23] the intergrowth plate should be TiC. The HRTEM image also exhibits that the atoms in the plate are different from the $\mathrm{Ti}_{2} \mathrm{AlC}$. It can be inferred that the growth of $\mathrm{Ti}_{2} \mathrm{AlC}$ phase leads to the lack of Al elements in neighbor area, which promote the $\mathrm{TiC}$ plate to form. And then it is reasonable to understand that the special microtwins in $\mathrm{TiC}$ phase, which may be the $\mathrm{Ti}_{2} \mathrm{AlC}$ 
plates. Such ceramic particle inside should be attributed to the ball milling and the high temperature during SHS/HE, which result in the $\mathrm{Al}$ elements segregate in the TiC.

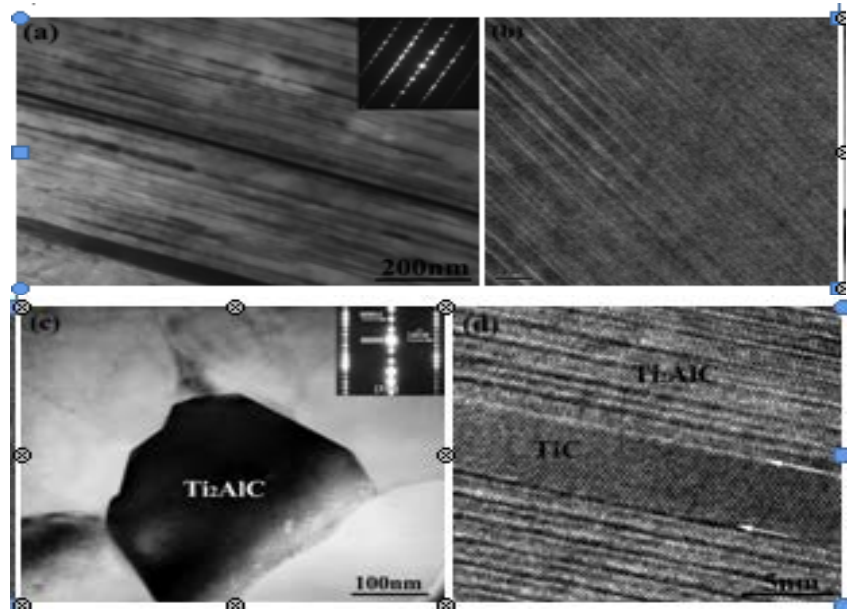

FIGURE III. (A) BRIGHT FIELD TEM MICROGRAPH OF TIC PARTICLES WITH STACKING FAULT AND MICROTWINS INSIDE, (B) HRTEM IMAGE OF THE STACKING FAULT AND MICROTWINS, (C) MORPHOLOGY OF THE TI2ALC PARTICLE, (D) HRTEM IMAGE SHOWING THE INTERGROWTH OF TIC AND TI2ALC (INSET PICTURES SHOWING THE SAED PATTERNS).

\section{CONCLUSIONS}

(1) An in-situ NiAl-TiC- $\mathrm{Al}_{2} \mathrm{O}_{3}$ composite has been successfully fabricated from elemental powders using thermal explosion and hot extrusion. In the composite, TiC particles along NiAl grain boundary tend to agglomerate and grow, but the TiC particles in NiAl grain still keep polygonal and faceted. The $\mathrm{NiAl}$ grain of the composite matrix has been greatly refined by the in situ formed $\mathrm{TiC}$ particles. In addition, the $\mathrm{Ti}_{2} \mathrm{AlC}$ particle with hexagonal crystal is formed along the $\mathrm{NiAl}$ grain boundary.

(2) The interface between $\mathrm{NiAl}$ and $\mathrm{TiC}$ is flat and sharp, and almost no interfacial precipitate, but, in some cases, thin amorphous layer is observed at the interface. The stacking fault and microtwins are also observed in many TiC particles, and moreover $\mathrm{TiC}$ is intergrowth within $\mathrm{Ti}_{2} \mathrm{AlC}$ in some particles.

\section{ACKNOWLEDGMENT}

The authors are grateful to the Strategic New Industry Development Special Foundation of Shenzhen (JCYJ20140419114548515 and JCYJ20130402172114948), the Shenzhen International Cooperative Research Project (GJHZ20140419114548516) and the Shenzhen Technology Innovation Plan (CXZZ20140419114548507 and CXZZ20140731091722497).

\section{REFERENCES}

[1] R. Darolia, NiAl alloys for high-temperature structural applications, JOM 43(1991) 44-49.

[2] L.Y. Sheng, W. Zhang, J. T. Guo, F. Yang, Y. C. Liang, H. Q. Ye, Effect of Au addition on the microstructure and mechanical properties of NiAl intermetallic compound, Intermetallics 18(2010)740-744.
[3] L.Y. Sheng, Y. Xie, T. F. Xi, J. T. Guo, Y. F. Zheng, H. Q. Ye, Microstructure characteristics and compressive properties of NiAl-based multiphase alloy during heat treatments, Mater. Sci. Eng. A 528(2011)8324-8331.

[4] L. Y. Sheng, F. Yang, T. F. Xi, C. Lai, J. T. Guo, Microstructure and elevated temperature tensile behaviour of directionally solidified nickel based superalloy, Mater. Res. Innov. 17(2013) S101-S106.

[5] S. C. Deevi, V. K. Sikka, C. T. Liu, Processing, properties, and applications of nickel and iron aluminides, Prog. Mater. Sci. 42(1997)177-192.

[6] L. Y. Sheng, F. Yang, T. F. Xi, J. T. Guo, H. Q. Ye, Microstructure evolution and mechanical properties of $\mathrm{Ni3Al} / \mathrm{Al} 2 \mathrm{O} 3$ composite during self-propagation high-temperature synthesis and hot extrusion, Mater. Sci. Eng. A 555(2012)131-138.

[7] L. Y. Sheng, J. T. Guo, W. L. Ren, Z. X. Zhang, Z. M. Ren, H. Q. Ye, Preliminary investigation on strong magnetic field treated NiAl-Cr(Mo)-Hf near eutectic alloy, Intermetallics 19(2011)143-148.

[8] L.Y. Sheng, W. Zhang, C. Lai, J.T. Guo, T.F. Xi, H.Q. Ye, Microstructure and mechanical properties of laves phase strengthening $\mathrm{NiAl}$ base composite fabricated by rapid solidification, Acta Metall. Sin. 49(2013):1318-1324.

[9] L. Y. Sheng, W. Zhang, J. T. Guo, Z. S. Wang, H. Q. Ye, Microstructure evolution and elevated temperature compressive properties of a rapidly solidified NiAl-Cr(Nb)/Dy alloy, Mater. Design 30(2009)2752-2755.

[10] L.Y. Sheng, C. Lai, F. Yang, Q.L. Wang, T.F. Xi, Microstructure and wear behaviour of ceramic particles strengthening $\mathrm{NiAl}$ based composite, Mater. Res. Innov. 18(2014):S544-S549.

[11] L.Y. Sheng, L.J. Wang, T.F. Xi, Y.F. Zheng, H.Q. Ye, Microstructure, precipitates and compressive properties of various holmium doped $\mathrm{NiAl} / \mathrm{Cr}(\mathrm{Mo}, \mathrm{Hf})$ eutectic alloys, Mater. Design 32(2011):4810-4817.

[12] L. Y. Sheng, J. T. Guo, T. F. Xi, B. C. Zhang, H. Q. Ye, ZrO2 strengthened $\mathrm{NiAl} / \mathrm{Cr}(\mathrm{Mo}, \mathrm{Hf})$ composite fabricated by powder metallurgy, Prog. Nat. Sci.-Mater. Int. 22(2012)231-236.

[13] H. Choo, P. Nash, M. Dollar, Mechanical properties of NiAl-AlN-Al2O3 composites, Mater. Sci. Eng. A 239-240(1997)464-471.

[14] L. Y. Sheng, T. F. Xi, C. Lai, J. T. Guo, Y. F. Zheng, Effect of extrusion process on microstructure and mechanical properties of Ni3Al-B-Cr alloy during self-propagation high-temperature synthesis, Trans. Nonferrous Met. Soc. China, 22(2012)489-495.

[15] W. J. Ye, D. Feng, H. L. Luo, The microstructure and its properties of Ni3Al based composite, Mater. Res. Innov. 2(1999)321-324.

[16] L. Y. Sheng, W. Zhang, J. T. Guo, Z. S. Wang, V. E. Ovcharenko, L. Z. Zhou, H. Q. Ye, Microstructure and mechanical properties of Ni3Al fabricated by thermal explosion and hot extrusion, Intermetallics 17(2009)572-577.

[17] O. Ozdemir, S. Zeytin, C. Bindal,A study on NiAl produced by pressure-assisted combustion synthesis, Vacuum 84(2009)430-437.

[18] L. Y. Sheng, F. Yang, T. F. Xi, J. T. Guo, H. Q. Ye, Microstructure evolution and mechanical properties of $\mathrm{Ni3Al} / \mathrm{Al} 2 \mathrm{O} 3$ composite during self-propagation high-temperature synthesisand hot extrusion, Mater. Sci. Eng. A 555(2012)131-138.

[19] L. Y. Sheng, F. Yang, T. F. Xi, J. T. Guo,Investigation on microstructure and wear behavior of the NiAl-TiC-Al2O3 composite fabricated by self-propagation high-temperature synthesis with extrusion, J. Alloys Compd. 554(2013)182-188.

[20] L.Y. Sheng, F. Yang, T.F. Xi, Y.F. Zheng, J.T. Guo, Microstructure and room temperature mechanical properties of $\mathrm{NiAl}-\mathrm{Cr}(\mathrm{Mo})-(\mathrm{Hf}, \mathrm{Dy})$ hypoeutectic alloy prepared by injection casting, Trans. Nonferrous Met. Soc. China 23(2013)983-990.

[21] R. Yu, L.L. He, H.Q. Ye, Effects of Si and $\mathrm{Al}$ on twin boundary energy of TiC, Acta Mater. 51(2003)2477-2484

[22] L. Y. Sheng, F. Yang, J. T. Guo, T. F. Xi, H. Q. Ye, Investigation on NiAl-TiC-Al2O3 composite prepared by selfpropagation high temperature synthesis with hot extrusion, Compos. B-Eng. 45(2013)785-791.

[23] L.Y. Sheng, F. Yang, J.T. Guo, T.F. Xi, Anomalous yield and intermediate temperature brittleness behaviors of directionally solidified 
nickel-based superalloy, Trans. Nonferrous Met. Soc. China 24 (2014) 673-681. 